\title{
Gene expression profiling of human HBV-and/or HCV-associated hepatocellular carcinoma cells using expressed sequence tags
}

\author{
SUN YOUNG YOON ${ }^{1}$, JEONG-MIN KIM ${ }^{1}$, JUNG-HWA OH ${ }^{1}$, YEO-JIN JEON ${ }^{1}$, DONG-SEOK LEE ${ }^{1}$, \\ JOO HEON KIM ${ }^{3}$, JONG YOUNG CHOI ${ }^{4}$, BYUNG MIN AHN ${ }^{5}$, SANGSOO KIM ${ }^{2}$, \\ HYANG-SOOK YOO ${ }^{1}$, YONG SUNG KIM ${ }^{1}$ and NAM-SOON KIM ${ }^{1}$
}

\begin{abstract}
${ }^{1}$ Laboratory of Human Genomics, Genome Research Center, Korea Research Institute of Bioscience and Biotechnology (KRIBB), Daejeon 305-333; ${ }^{2}$ Department of Bioinformatics and Life Science, Soongsil University, Seoul; ${ }^{3}$ Department of Pathology, Eulji University School of Medicine, Daejeon 301-832; ${ }^{4}$ Department of Internal Medicine, Catholic University of Medicine, 137-701 Seoul; ${ }^{5}$ Department of Internal Medicine, Catholic University of Medicine, Daejeon 301-723, Korea
\end{abstract}

Received November 14, 2005; Accepted January 19, 2006

\begin{abstract}
Liver cancer is one of the leading causes of cancer death worldwide. To identify novel target genes that are related to liver carcinogenesis, we examined new genes that are differentially expressed in human hepatocellular carcinoma (HCC) cell lines and tissues based on the expressed sequence tag (EST) frequency. Eleven libraries were constructed from seven HCC cell lines and three normal liver tissue samples obtained from Korean patients. An analysis of gene expression profiles for HCC was performed using the frequency of ESTs obtained from these cDNA libraries. Genes were identified ( $\mathrm{n}=120)$ as being either up- or downregulated in human liver cancer cells. Among these, 14 genes (FTL, K-ALPHA1, LDHA, RPL4, ENO1, ANXA2, RPL9, RPL10, RPL13A, GNB2L1, AMBP, GC, A1BG, and $S E R P I N C 1$ ), in addition to previously well-known liver cancer related genes, were confirmed to be differentially expressed in seven liver cancer cell lines and 17 HCC tissues by semi-quantitative RT-PCR. In addition, 73 genes, in which there was a significant difference $(\mathrm{P}>0.99)$ between $\mathrm{HBV}$ - and HCV-associated HCC cells, were selected. Of these, expression patterns of 14 (RPLPO, AKRIC, KRT8, GPX4, RPS15, ID1, RPS21, VIM, EEF1G, EIF4A1, HLA-C, $F N 1, C D 44$, and RPS10) were confirmed by semiquantitative RT-PCR in four of HBV- and three of HCVassociated HCC cell lines. Among those genes, an immunohistochemical analysis for ANXA2 showed that it is
\end{abstract}

Correspondence to: Dr Nam-Soon Kim and Dr Yong Sung Kim, Laboratory of Human Genomics, Genome Research Center, Korea Research Institute of Bioscience and Biotechnology (KRIBB), P.O. Box 115, Yusong, Daejeon 305-333, Korea

E-mail: nskim37@kribb.re.kr

Key words: expression profiling, expressed sequence tag frequency, hepatocellular carcinoma expressed at high levels in HCC. Using an analysis of EST frequency, the newly identified genes, especially ANXA2, represent potential biomarkers for HCC and useful targets for elucidating the molecular mechanisms associated with $\mathrm{HCC}$ involving virological etiology.

\section{Introduction}

Liver cancer is one of the leading causes of cancer death worldwide. Hepatocellular carcinoma (HCC) is the most common primary cancer of the liver. Major risk factors for $\mathrm{HCC}$ are chronic hepatitis resulting from infection with HBV or $\mathrm{HCV}$ and exposure to various exogenous carcinogens, including aflatoxin B1 (1). Studies have shown that the incidence of HCC has substantially increased in East Asia, including Korea and Japan (2,3). Since most patients suffering from HCC do not survive long-term, a great deal of interest and urgency has developed regarding identifying novel HCC diagnostic markers for early detection and cancer-specific related genes as potential therapeutic targets in the treatment of HCC (4). Therefore, different markers are needed to correctly diagnose HCC.

Liver carcinogenesis is a multi-step process involving a variety of genetic alterations. The molecular mechanisms of hepatocarcinogenesis are not well understood, although aneuploidy and multiple genetic alterations are frequently present. It is noteworthy that mutations of $\mathrm{p} 53, \mathrm{Rb}$ and $\beta$-catenin, as well as the overexpression of c-myc and cyclin D1, have been reported in HCC (5-8). A loss of heterozygosity $(\mathrm{LOH})$ at multichromosomal loci has also been frequently reported in human HCC (9-11). In addition, several growth factors such as TGF $\alpha$ and $\beta$ are known to be implicated in the development of $\operatorname{HCC}(12,13)$. An analysis of the gene expression profile in HCC using a microarray has also been reported (14-17). Shirota et al reported that transcriptional factors or tissue-specific expression proteins were related to cell differentiation or the development of HCC (14). In addition, it has been reported that mitosis-promoting genes are up-regulated in HCC (17). Genes involved in cell cycle regulation such as cyclin, cyclin-dependent kinases, and cell 
Table I. Primer sequences for semi-quantitative RT-PCR.

\begin{tabular}{|c|c|c|}
\hline Genes & Forward $\left(5^{\prime} \rightarrow 3^{\prime}\right)$ & Reverse $\left(5^{\prime} \rightarrow 3^{\prime}\right)$ \\
\hline \multicolumn{3}{|c|}{ HCC vs. Normal } \\
\hline FTL & ATGAGCTCCCAGATTCGTCA & CCAGGAAGTCACAGAGATGG \\
\hline K-ALPHA-1 & GGCTTCAAGGTTGGCATC & ССТСТССТТСТТССТСАСС \\
\hline LDHA & ATGGCAACTCTAAAGGATCA & GCAACTTGCAGTTCGGGC \\
\hline RPL4 & GAGCTGGCAAAGGCAAA & TCCGGCGCATGGTCTTT \\
\hline EN01 & GACTTGGCTGGCAACTCTG & GGTCATCGGGAGACTTGAA \\
\hline ANXA2 & ATGTCTACTGTTCACGAAAT & GCTCCTGGTTGGTTCTGG \\
\hline RPL9 & ATGAAGACTATTCTCAGCAATC & TGAACAAGCAACACCTGGTC \\
\hline RPL10 & ATGGGCCGCCGCCCCGCC & TGAGTGCAGGGCCCGCCA \\
\hline RPL13A & ATGGCGGAGGTGCAGGTC & GACCAGGAGTCCGTGGGT \\
\hline GNB2L1 & AACCACATTGGCCACACA & TGCCAATGGTCACCTGC \\
\hline AMBP & AGTGGTACAACCTGGCCATC & ACAGCCCTCCGGACTCTC \\
\hline GC & ATGAAGAGGGTCCTGGTACTAC & TCATTTGTGGGTTCCACGTA \\
\hline A1BG & ATGTCCATGCTCGTGGTCTT & TCAGGCACCTCCAGAAACTC \\
\hline SERPINC1 & ATGTATTCCAATGTGATAGGAA & TCAGTTGCTGGAGGGTGTC \\
\hline \multicolumn{3}{|c|}{ HBV-HCC vs. HCV-HCC } \\
\hline RPLPO & GTTGCTGGCCAATAAGGT & GCCAAGAAGGCCTTGACC \\
\hline AKR1CN & AACTTCAACCACAGGCTGCT & ACACCTGCACGTTCTGTCTG \\
\hline KRT8 & CTGCTGGAGGGCGAGGA & CAGCGCAGGAGGGGTAG \\
\hline GPX4 & CAGTGAGGCAAGACCGAAGT & GGGGCAGGTCCTTCTCTATC \\
\hline RPS15 & СТTCCGCAAGTTCACCTACC & GGGCTTGTAGGTGATGGAGA \\
\hline ID1 & GGTGCGCTGTCTGTCTGAG & CTGATCTCGCCGTTGAGG \\
\hline RPS21 & GCGAGTTCGTGGACCTGTA & CCAATCGGAGAATGGAATCA \\
\hline VIM & ATGTCCACCAGGTCCGTG & TCGTTGGTTAGCTGGTCCAC \\
\hline EEF1G & AGGCGCTGGCTGCTGAG & CGTAGTCCACCTGCCAATC \\
\hline EIF4A1 & CTGGCCGTGTGTTTGATATG & TGTCCAGCTTCCACTCCTCT \\
\hline HLA-C & TGGGGAGGACCAAACTCA & GCAGCTCCCTCCTTTTCC \\
\hline FN1 & CCAACCTACGGATGACTCGT & TGGCACCGAGATATTCCTTC \\
\hline CD44 & GGCCAGCAAGTCTCAGGA & AGGCCTCCAAGTGGGAAC \\
\hline RPS10 & AGACAAGAATGTGCCCAACC & GGGGCAGATGAAGGTAATCA \\
\hline B2M & CTCGCTCCGTGGCCTTAG & CAAATGCGGCATCTTCAA \\
\hline
\end{tabular}

cycle negative regulators have also been reported to be down-regulated (15).

The application of global approaches such as the collection of expressed sequence tags (ESTs), Serial Analysis of Gene Expression (SAGE) and microarray techniques have been shown to be useful in the analysis of complex biological phenomena, including human diseases (15,17-21). Among these approaches, the expressed sequence tags (ESTs) generated by the single-pass sequencing of randomly selected cDNA clones from cDNA libraries have been used to identify novel genes (22). ESTs have also been found to be useful for the differential and quantitative analysis of expression patterns (23), and evaluation of gene expression profiles in a specific tissue (22-24). Therefore, it is evident that the identification and cataloging of genes associated with liver carcinogenesis, obtained by detailed gene expression profiles, would facilitate the elucidation of the molecular mechanisms of liver carcinogenesis.

To identify the genes associated with HCC by examining their expression profiles, we collected a large number of genes that are expressed in HCC cell lines or tissues. In particular, we applied a strategy for obtaining full-length cDNAs, since these clones are a valuable resource for the functional study of genes. As a first step, we constructed eleven full-length enriched cDNA libraries from HCC cell lines and tissues from Korean patients $(25,26)$. Using the EST frequency obtained from the liver EST data, the expression profile of the genes expressed in HCC cell lines and tissues was analyzed, and genes that are differentially expressed between HCC and normal tissues were selected as candidate markers for the diagnosis of HCC. Here, we report on the identification of genes containing $\mathrm{HBV}$ and/or $\mathrm{HCV}$ that are related to $\mathrm{HCC}$. 


\section{Materials and methods}

Cell culture, tissue samples and RNA preparation. The four different cell lines established from Korean HCC patients, SNU354, SNU368, SNU387 and SNU475, were hepatitis B surface antigen-positive and obtained from the Korean Cell Line Bank (http://cellbank.snu.ac.kr/) (27). Three different cell lines established from Korean HCC patients with $\mathrm{HCV}$ positive HLK1, HLK3 and JSHC were obtained from the Chonbuk National University Medical School and Hospital, Korea (28). All seven cell lines were maintained at $37^{\circ} \mathrm{C}$ in humidified air containing $5 \% \mathrm{CO}_{2}$ using Dulbecco's modified Eagle's medium (DMEM; Gibco BRL, Gaithersburg, MD) supplemented with $10 \%$ fetal bovine serum.

The three normal liver tissues, N779227, N800102 and N803806, were used to construct the cDNA libraries, and obtained from necropsy in the Catholic University of Medicine, Daejeon, Korea. Seventeen tissues with pairs of HCC tumors and adjacent non-tumor tissue were collected at the Catholic University of Medicine, Seoul, Korea. All patients participating in this study gave their informed consent before surgery. The HCCs were classified as grade I $(n=3)$, II $(n=5)$, III $(n=5)$ and IV $(n=4)$, respectively, corresponding to the criteria of Edmondson and Steiner (29).

Total RNA was extracted from the cultured cells and tissues using a commercially available RNA Isolation kit (Qiagen, Hilden, Germany) following the procedures recommended by the manufacturer.

Construction of cDNA library and DNA sequencing. The full-length cDNA library was constructed using an improved capping method (25). Plasmid DNAs were extracted from clones that had been randomly selected from the constructed cDNA libraries using an MWG Plasmidprep 96 (MWG Biotechnology, Ebersberg, Germany). DNA sequencing was performed using previously described procedures (30).

Bioinformatic analysis of ESTs. Analysis of the collected ESTs with a bioinformatic tool was performed following previously described procedures (30). The annotation of 'high quality' liver ESTs were carried out using the human mRNA subset extracted from the GenBank database and UniGene database (Hs.seq.all, build \#163) for similarity comparisons using BLASTN. For a protein similarity assessment, a comparison was performed against the nonredundant protein database using BLASTX.

Gene expression analysis. The frequency of each gene was analyzed by dividing the number of ESTs of a gene by the number of total clones merged into the UniGene database build \#163 in each library. Genes that were abundantly expressed in each cDNA library were selected and listed from among ESTs showing an expression frequency of $\geq 0.11 \%$. Significant differences in gene expression between the data sets were calculated using a previously described method (31). Analysis of expressional differences between the normal pool and HCC pool was performed with a cut-off probability of 0.999 . The same analysis, substituting an expression frequency of $\geq 0.1 \%$ and a cut-off probability of 0.99, was also performed for the HBV pool and HCV pool.
The gene list was sorted according to gene frequency in the pool of the overexpressing gene.

The Gene Ontology (GO) database (www.geneontology.org/ \#godatabase) was used to classify the gene profiles into the gene ontology. Each UniGene cluster was mapped to LocusLink (as of April 21, 2004), then assigned GO IDs, as in the LocusLink database.

Semi-quantitative RT-PCR. Reverse transcription (RT) was performed with $5 \mu \mathrm{g}$ of isolated RNA using previously described procedures (30). To quantify the amounts of first cDNAs, the RT solution mixed with a human B2M competitor DNA was used as the template for PCR. PCR was performed according to the method of Kim et al (30); conditions were 1 cycle for $2 \mathrm{~min}$ at $94^{\circ} \mathrm{C}$, and 25 cycles of $94^{\circ} \mathrm{C}$ for $30 \mathrm{sec}$, $55^{\circ} \mathrm{C}$ for $1 \mathrm{~min}$, and $72^{\circ} \mathrm{C}$ for $1 \mathrm{~min}$ with $\mathrm{B} 2 \mathrm{M}$ primers (Table I). The concentration of the first cDNA of each sample was adjusted based on the amounts of PCR product of B2M competitor DNA. To validate the expression level of the selected genes, PCR was performed using adjusted first cDNAs as templates and a specific primer set for each gene (Table I) with the same conditions used in the above PCR. The transcriptional activity of each gene in the HCC cell lines was calculated relative to the average amount of target gene in normal tissues for up-regulated genes in the HCC pool or relative to that of cancer cells for down-regulated genes in the HCC pool, and are presented as the relative fold expression change (log base 2) after normalization against a $\mathrm{B} 2 \mathrm{M}$ standard. On the other hand, the transcript levels of target genes in HCC tissues were calculated relative to the amount of target gene in the corresponding non-tumor liver tissue, and are presented as the relative fold expression change (log base 2) after normalization against B2M. In addition, the transcript levels of the up- or down-regulated target genes in HBV-HCC cell lines were calculated using the same method, except that they were done relative to the average amount of target gene in the HCV pool for up-regulation in the HBV pool or relative to that of the HBV pool for up-regulation in the HCV pool. The amount of B2M product in each cell line and tissue was calculated from a standard curve.

Immunohistochemistry. Immunohistochemical staining of ANXA2 in HCC tissues was performed using the same previously described procedures (32). A goat polyclonal antibody against ANXA2 (Santa Cruz Biotechnology, Inc., Santa Cruz, CA) was used as the primary antibody. These antibodies were used at a dilution of 1:100 for ANXA2.

\section{Results}

Large-scale ESTs collection from human HCC cells and tissues. Eleven full-length cDNA libraries were constructed from seven HCC cell lines and three normal liver tissues obtained from Korean patients. A total of 20,354 clones were randomly selected from these 10 libraries and used for 5 ' end single-pass sequencing. The obtained sequences were subjected to quality control procedures, namely trimming of the vector region and removal of low quality or short $(<100 \mathrm{bp})$ sequences. Finally, 18,831 high quality ESTs with an average length of $500 \mathrm{bp}$ were collected (Table II). After screening 
Table II. Summary of cDNA libraries.

\begin{tabular}{|c|c|c|c|c|c|}
\hline \multirow[b]{2}{*}{ Source } & \multirow[b]{2}{*}{ Library } & \multirow[b]{2}{*}{ Vector } & \multirow[b]{2}{*}{ Reads } & \multicolumn{2}{|c|}{ Unigene $163^{\mathrm{a}}$} \\
\hline & & & & Clones & Clusters \\
\hline \multicolumn{6}{|c|}{ HCC cell lines } \\
\hline \multicolumn{6}{|l|}{ HBV-HCC } \\
\hline SNU475 & L3 SNU475 & pCNS-D2 & 2336 & 2233 & 1011 \\
\hline SNU368 & L4SNU368 & pCNS-D2 & 2524 & 2445 & 834 \\
\hline \multirow[t]{2}{*}{ SNU354 } & L9SNU354 & pT7T3-Pac & 1516 & 1194 & 913 \\
\hline & L11SNU354 & pCNS-D2 & 1958 & 1627 & 1089 \\
\hline SNU387 & L13SNU387 & pCNS-D2 & 1181 & 1153 & 545 \\
\hline \multicolumn{6}{|l|}{ HCV-HCC } \\
\hline HLK1 & L5HLK1 & pCNS-D2 & 3601 & 3495 & 1492 \\
\hline JSHC & L12JSHC & pCNS-D2 & 1005 & 981 & 556 \\
\hline HLK3 & L16HLK3 & pT7T3-Pac & 2429 & 2110 & 1426 \\
\hline \multicolumn{6}{|c|}{ Normal tissues } \\
\hline N800102 & L7N800102 & pCNS-D2 & 1466 & 1349 & 503 \\
\hline N779227 & L19N779227 & pCNS-D2 & 1254 & 1209 & 373 \\
\hline N803806 & L20N803806 & pCNS-D2 & 1084 & 1035 & 331 \\
\hline Total & & & 20354 & 18831 & 5901 \\
\hline
\end{tabular}

${ }^{a}$ Number of clones and clusters in NCBI Unigene Build 163 contributed by our EST sequences.

out the ESTs derived from mitochondrial DNAs, ribosomal DNAs and human repetitive sequences, the remaining sequences were submitted to the NCBI dbEST database (accession nos. CB105131-CB164813). When all of our ESTs were annotated by coalescing into human UniGene clusters (build 163), they were assembled into 5,901 clusters. Most were ESTs coding a known gene having an identity of at least $95 \%$ with human Refseq or mRNA. These annotated results were used in subsequent analyses of expression profiles.

Identification of HCC related genes. To identify the candidate genes related to human liver carcinogenesis, we divided the constructed libraries into two groups, a 'normal pool' and an 'HCC pool'. The normal pool was composed of three libraries of normal tissues and the HCC pool of eight libraries of cancer cells. We then selected 120 genes that had a frequency of $>0.11 \%$ on average in each pool and showed a significant difference $(\mathrm{P}>0.999)$ between the two pools. We found 40 up-regulated genes and 80 down-regulated genes in the HCC pool, as shown in Table III.

Among the up-regulated genes in the HCC pool, significant differences were observed in the gene groups associated with cell structure formation ( $K$-ALPHA-1 and $A C T B$ ), the glycolysis pathway (LDHA, ENO1, and $P G K 1$ ), heat shock proteins ( $H S P A 8$ and $H S P C B)$, cytoskeletal development (ANXA2 and TMSB10), and protein synthesis (RPL4, RPL9, RPLPO, RPL10, RPL13A, RPS8, RPL5, RPS12, RPL13, RPS20, RPL18A, RPS3A, RPS3, and RPS10). Although gene EEF1Al was relatively abundant in the normal pool, the frequency of this gene in the HCC pool was significantly higher than in the normal pool.
In the case of down-regulated genes in the HCC pool, significant differences were observed in the gene groups related to liver-specific genes $(A L B, O R M 1, C 1 R$, and $C 3)$, proteolysis and peptidolysis (HP, HPR, CPB2, and $A C Y 1)$, regulation and blood pressure $(F G G, F G B, K N G$, and $A G T)$, detoxification and drug metabolism (CYP2A6, MT2A, CYP2A7, $C Y P 2 E 1$, and $C Y P 2 C 8)$, lipid metabolism (APOH, APOA5, $R O D H-4, C Y P 3 A 4$, and $A P O A 1)$, glycometabolism (HPD and $F B P 1)$, alcohol metabolism $(A D H 1 C, A D H 1 B$, and $A D H 1 A)$, amino acid metabolism (AGXT and TAT), and the immune system (CD74, CD14, AZGP1, and SLC22A1).

Verification of HCC-related genes using semi-quantitative $R T$ $P C R$. To validate the up- and down-regulated genes in HCC selected from the EST frequency data, we randomly selected 13 up-regulated genes from the HCC pool (FTL, K-ALPHA-1, LDHA, RPL4, ACTB, ENO1, ANXA2, RPL9, RPLPO, RPL10, $V I M, R P L 13 A$, and GNB2L1), and 10 commonly downregulated genes from the $\mathrm{HCC}$ pool $(A L B, H P, A M B P, F G G$, $G C, F G B, A 1 B G, V T N$, SERPINC1, and FGA), and performed semi-quantitative RT-PCR on HCC cell lines and tumor tissues.

Fig. 1 reveals the expression levels of the 10 up-regulated genes and four down-regulated genes in liver cancers, except for the previously reported liver cancer related genes such as RPLPO, ACTB, VIM, ALB, HP, FGG, FGB, VTN and FGA. As shown in Fig. 1A, the results of RT-PCR in HCC cell lines show that all of the up-regulated genes were highly expressed in most of the HCC cell lines, but were either expressed at very low levels or not at all in normal tissues. On the other hand, all down-regulated genes were expressed at very low levels or not detected in all HCC cell lines, and 
Table III. Genes showing a significant difference in expression $\left(\mathrm{p}>0.999^{\mathrm{a}}\right)$ between normal liver tissues and liver cancer cell lines.

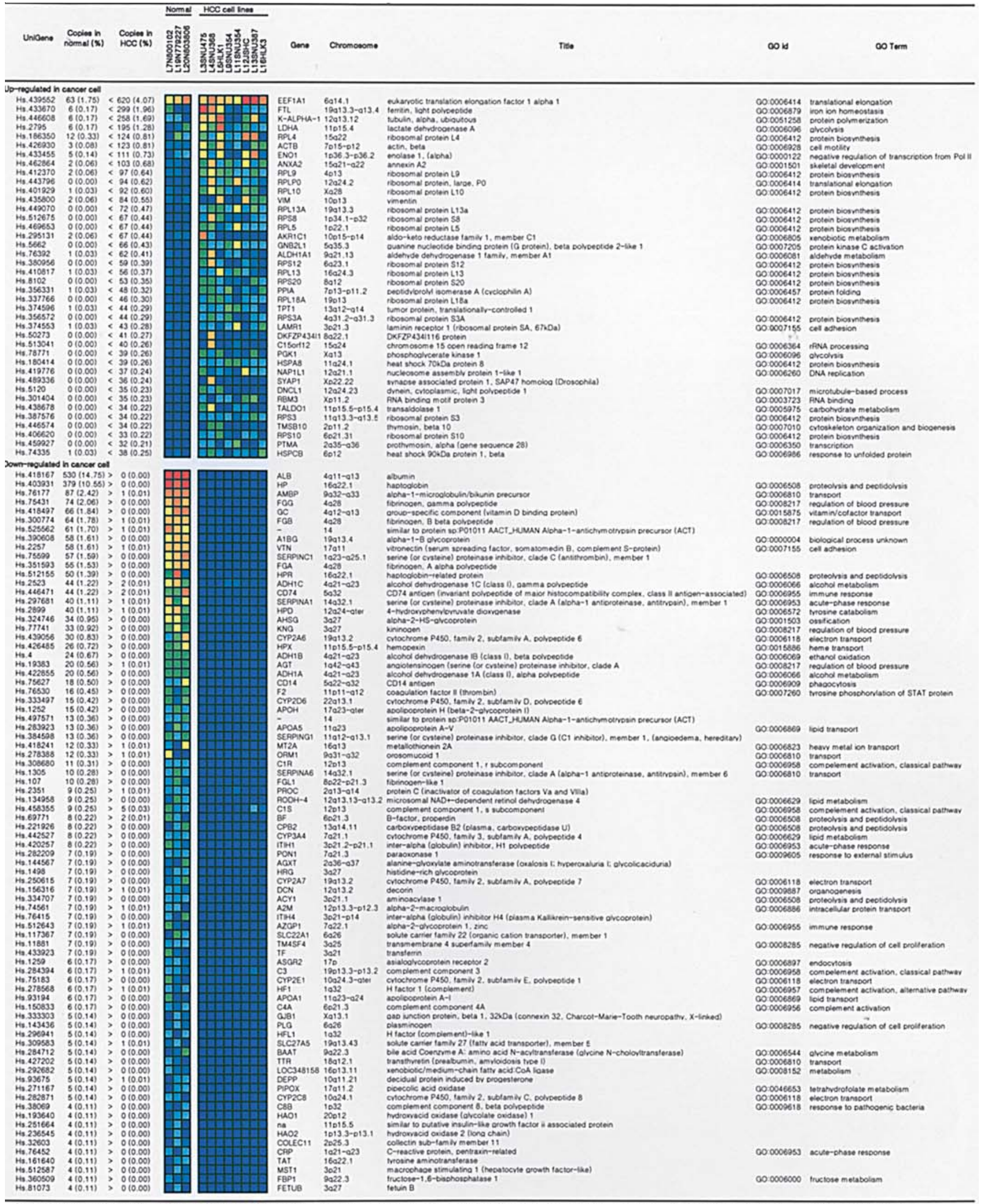

Colors indicate the frequency of a pene in each librar.

$0 \% \quad 0 . \quad 0.5 \quad 1 \quad \geq 5$

showed high expression levels in normal tissues (Fig. 1B). These results show that the transcriptional levels of the selected genes by semi-quantitative RT-PCR are consistent with the EST frequency data for all genes.
An expression analysis of the 14 confirmed genes in all 17 pairs of HCC tumor tissues and their corresponding nontumor tissues in stages I-IV was also performed. The results showed that the up-regulated genes were highly expressed in 


\section{(A) Up-regulated genes in $\mathrm{HCC}$ cell lines}
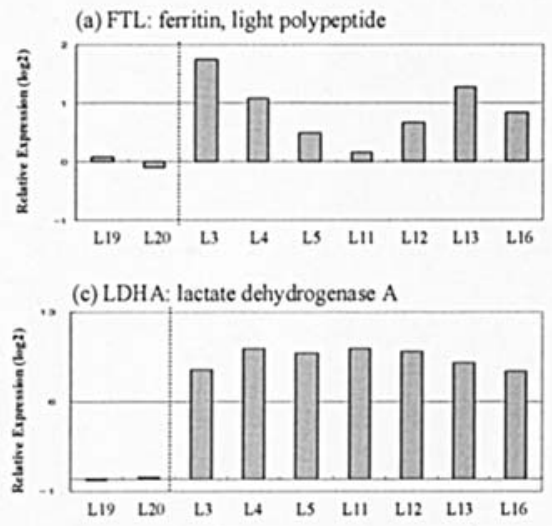

(c) ENO1: enolase I, (alpha)

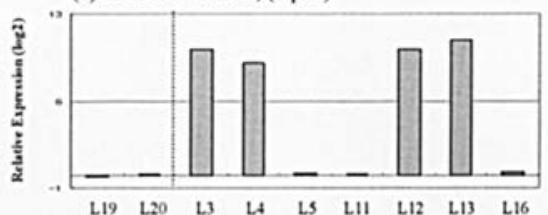

(g) RPL9: ribosomal protein L9

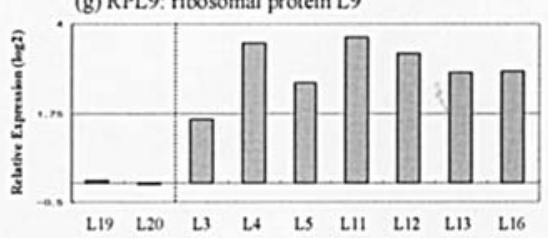

(i) RPL13A: ribosomal protein L13A

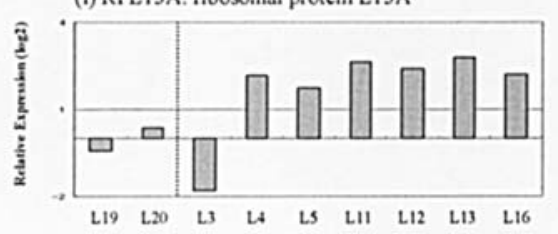

(b) K-ALPHA1: tubulin, alpha, ubiquitous

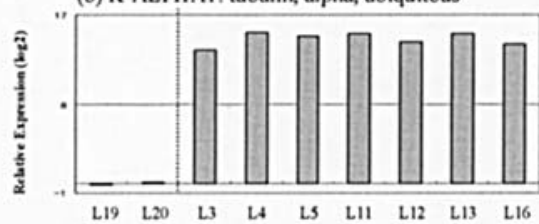

(d) RPL4: ribosomal protein L4

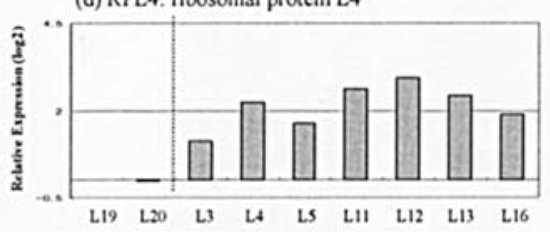

(f) ANXA2: annexin A2

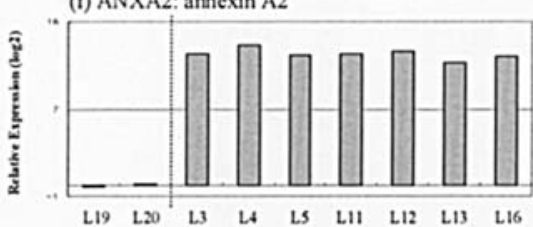

(h) RPL10: ribosomal protein $\mathrm{L} 10$

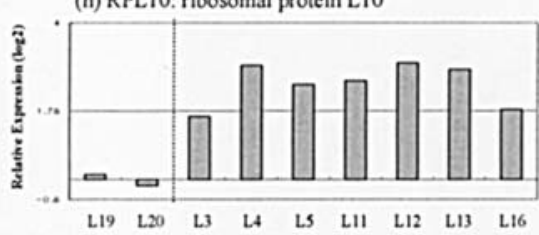

(j) GNB2LI: guanine nucleotide binding protein

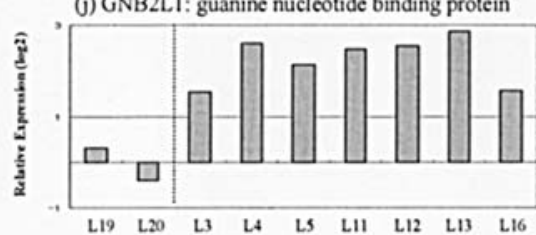

(B) Down-regulated genes in HCC cell lines

(a) AMBP: alpha-1-microglobulin/bikunin precursor

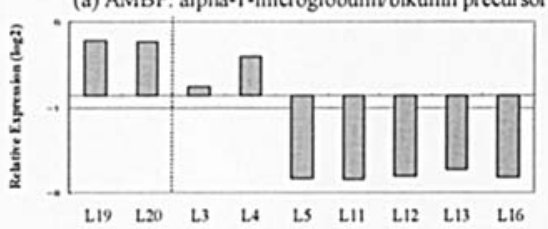

(c) A1BG: alpha-1-glycoprotein

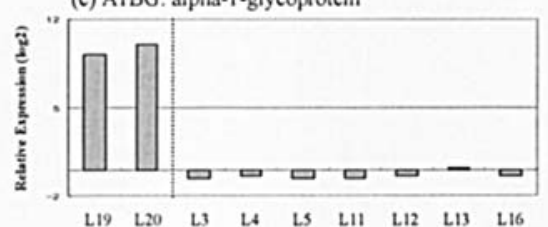

(b) GC: group-specific component

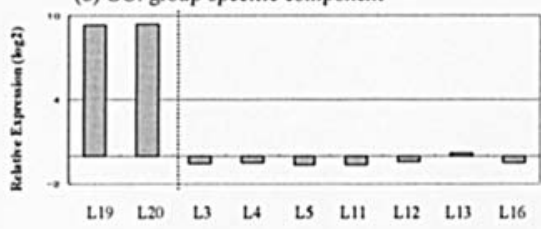

(d) SERPINC1: serine proteinase inhibitor

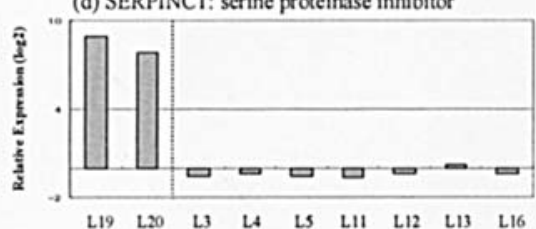

Figure 1. Semi-quantitative RT-PCR of the up- or down-regulated genes randomly selected from an HCC pool based on EST frequency in HCC cell lines. Total RNAs were extracted from normal tissues (L19, N779227; L20, N803806) and HCC cell lines (L3, SNU475; L4, SNU368; L5, HLK1; L11, SNU354; L12, JSHC; L13, SNU387; L16, HLK3) and used as templates for semi-quantitative RT-PCR (see Materials and methods for details). (A) Up-regulated and (B) down-regulated genes in the HCC pool. The transcript levels of target genes were calculated relative to the average amount of target gene in normal tissues (A) or relative to that of HCC cells (B), and are presented as the relative fold expression change (log base 2) after normalization against B2M. The amount of B2M product in each cell line and tissue was calculated from a standard curve. A positive value represents an up-regulated expression level, and a negative value represents a down-regulated expression level relative to the average amount of target gene.

most HCC tumor tissues compared to their corresponding non-tumor tissues (Fig. 2A). These genes were highly expressed in tumors with a frequency of 53\%-77\% in 17 HCC tissues. In particular, the highly expressed frequencies of these genes in $\mathrm{HCC}$ tumors were increased with increasing progression. In addition, the expression patterns of four down-regulated genes were also confirmed in HCC tumor tissues. These genes were expressed at low levels in HCC with a frequency of 59\%-76\% (Fig. 2B). The low expression level of these genes was detected in stages I to IV of HCC. 
(A) Up-regulated genes in HCC tissues
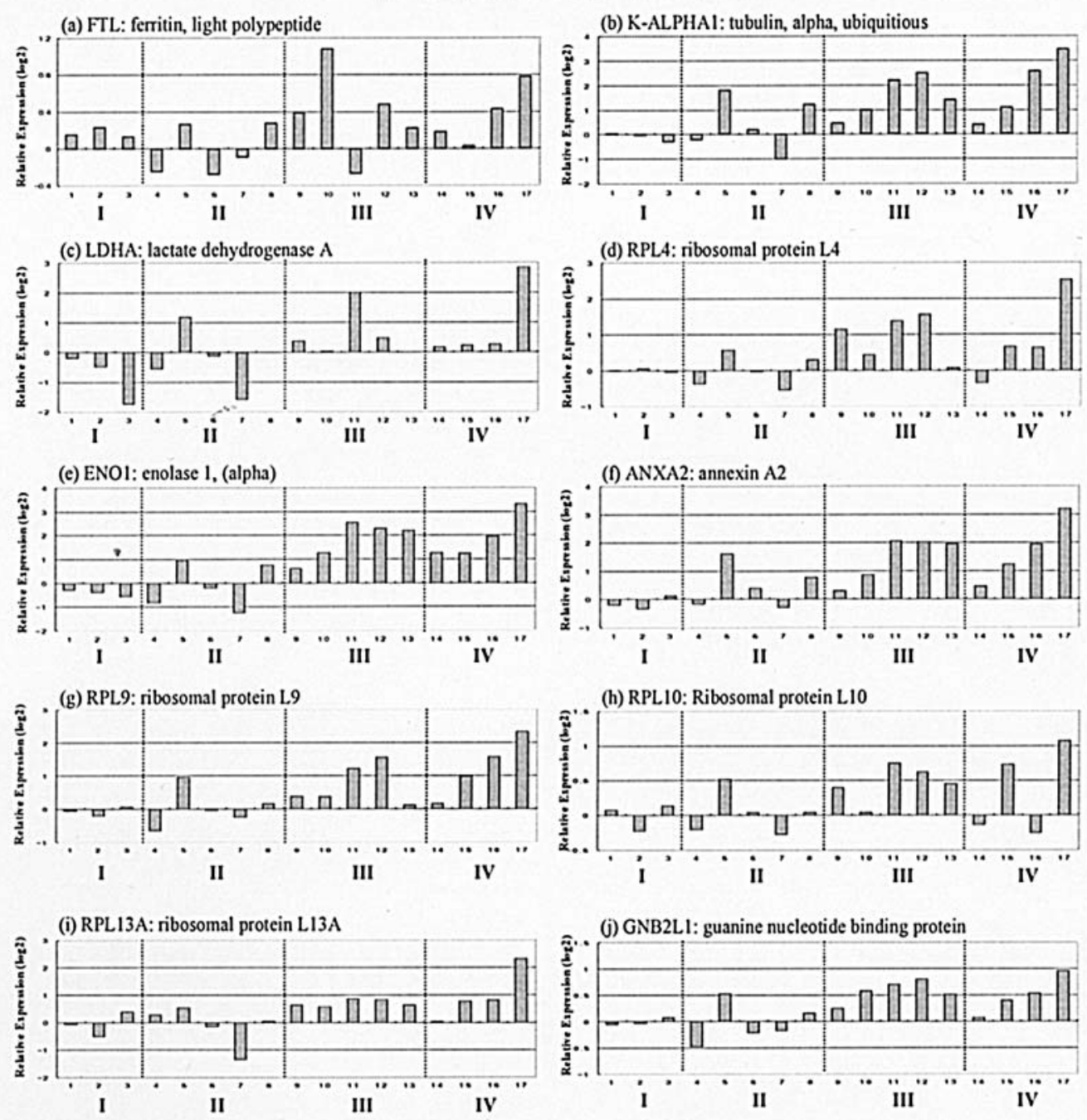

(B) Down-regulated genes in HCC tissues
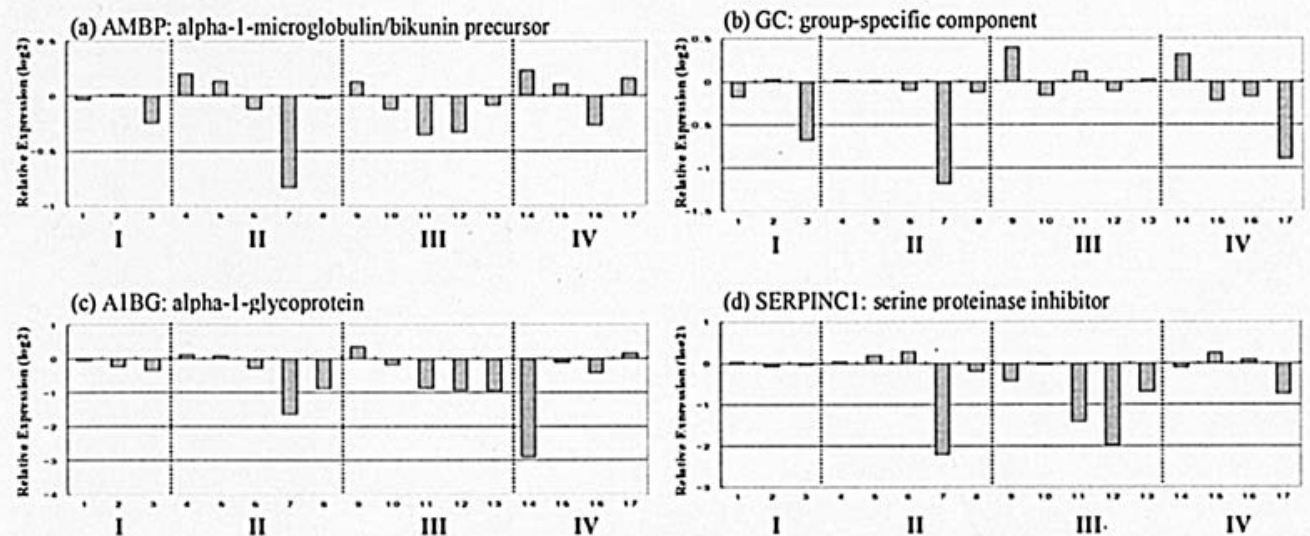

Figure 2. Semi-quantitative RT-PCR of the up- or down-regulated genes randomly selected from the HCC pool in HCC tissues. Total RNAs were extracted from $17 \mathrm{HCC}$ tumor samples and their corresponding non-tumor liver tissue samples, then used as templates for semi-quantitative RT-PCR. (A) Up-regulated and (B) down-regulated genes in the HCC pool. The transcript levels of target genes were calculated relative to the amount of target gene in their corresponding non-tumor liver tissue, and are presented as the relative fold expression change (log base 2) after normalization against B2M. I, II, III, and IV designate classified HCC grades corresponding to Edmonson and Steiner.

These results indicate that the confirmed data from semiquantitative RT-PCR are in good agreement with the EST frequency data. In addition, the mRNA levels of the target genes in liver tissues were largely consistent with those of the cell lines.
Identification of genes related to $\mathrm{HBV}$ - or $\mathrm{HCV}$-associated $H C C$. It has clearly been established that HBV and HCV infections are major risk factors for the development of HCC (1). We further analyzed the EST frequencies between both libraries of the HBV- and HCV-associated HCC cell lines to 
Table IV. Genes showing a significant difference in expression ( $p>0.99^{a}$ ) between HBV- and HCV-associated HCC cell lines.

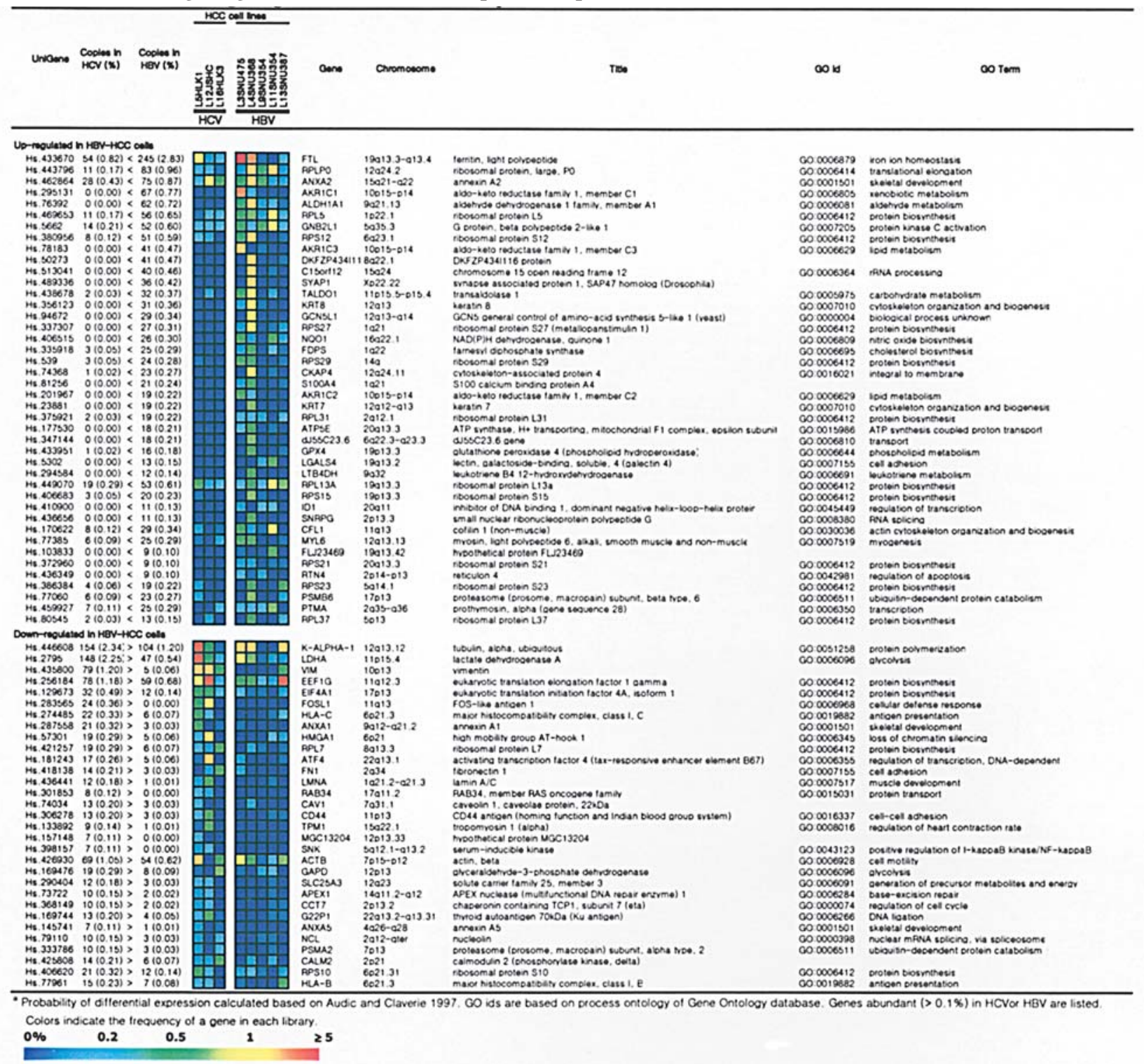

identify genes related to the virological features of HCC. The examined HCC cell lines were divided into two groups: 'HBV pool,' composed of HBV-positive HCC cell lines; and 'HCV pool,' composed of HCC cell lines established from HCV-positive HCC tissues. From this analysis, we isolated 73 genes with frequencies of $>0.1 \%$ on average from each pool and showing a significant difference $(\mathrm{P}>0.99)$ between the two pools, as shown in Table IV.

The genes in the HBV pool were found to contain 42 up-regulated genes (versus the HCV pool), which included genes such as FTL, GNB2L1, GCN5L1, FDPS, S100A4 and ID1. Most of these genes have not been reported as being related to the development and carcinogenesis of HBVassociated HCC. A functional classification of these selected genes showed that genes involved in protein synthesis (RPLP0, RPL5, RPS12, RPS27, RPS29, RPL31, RPL13A, RPS15, RPS21, RPS23, and RPL37), cytoskeletal organization (ANXA2, KRT8, CKAP4, KRT7, and CFL1), xenobiotic and lipid metabolism (AKR1C1, AKR1C3, NQO1, and AKR1C2), metabolism (ALDH1A1, TALDO1, GPX4, and LTB4DH) and transport (ATP5E and dj55C23.6) were included. In addition, we observed 31 down-regulated genes in the HCV pool. In this case, significant differences were found for genes such as VIM, FOSL1, HMGA1, ATF4 and LMNA. Many of these genes were involved in cell structure ( $K$-ALPHA-1 and $A C T B)$, glycolysis ( $L D H A$ and $G A P D)$, protein synthesis (EEFIG, EIF4A1, RPL7, and RPS10), antigen presentation (HLA-C and HLA-B), skeletal development (ANXAl and $A N X A 5)$, and cell adhesion (FN1 and CD44) according to the GO term.

Verification of the genes related to $H B V$ - or $H C V$-associated $H C C$ s using semi-quantitative RT-PCR. To more quantitatively examine our data for hepatitis-virus infection in HCC, we randomly selected 18 up-regulated genes from the HBV pool and 12 down-regulated genes from the HBV pool. The expression levels of these selected genes were confirmed by semi-quantitative RT-PCR analysis in the cell lines. In a comparison between RT-PCR data obtained from the HBV pool and HCV pool, approximately $70 \%$ of the up-regulated and down-regulated genes were in agreement with the EST frequency data (data not shown). Fig. 3 represents the results 
(A) Up-regulated genes in HBV-HCC cell lines

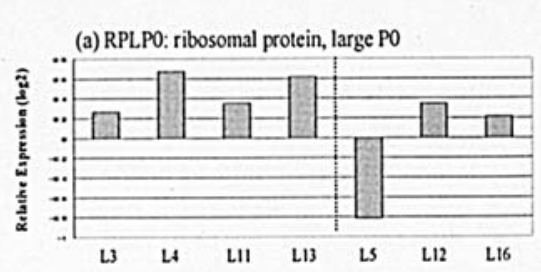

(c) KRT: keratin 8
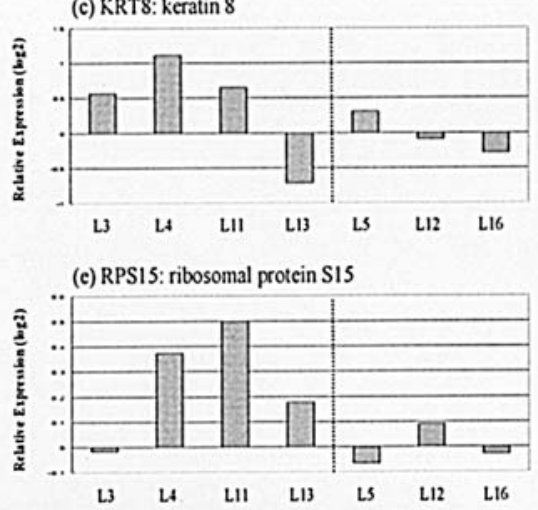

LI L LII LI3 LS L.12 L16

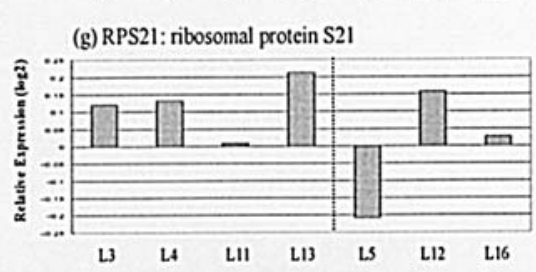

(b) AKRICN: aldo-keto reductase family 1, member C

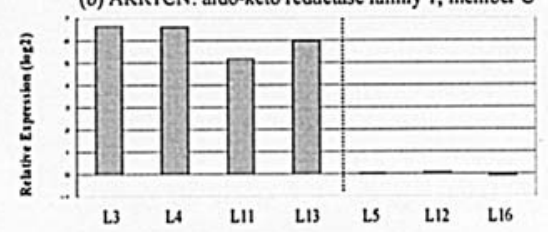

(d) GPX4: glutathione peroxidase 4

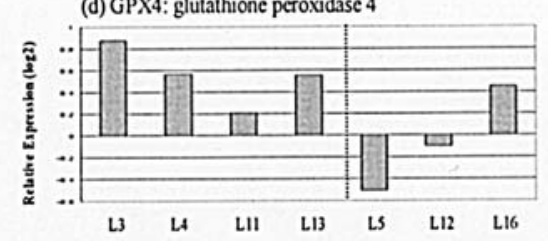

(f) ID1: inhibitor of DNA binding 1

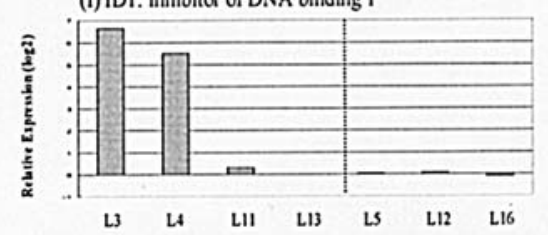

(B) Down-regulated genes in HBV-HCC cell lines

(a) VIM: vimentin

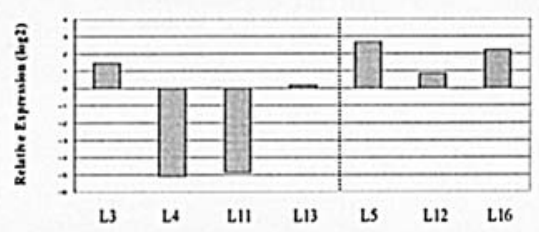

(c) EIF4Al: eukaryotic translation initiation factor $4 \mathrm{~A}$, isoform 1

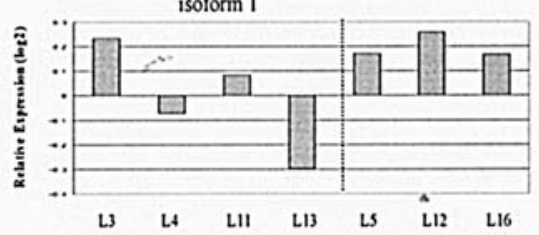

(e) FNI: fibronectin 1

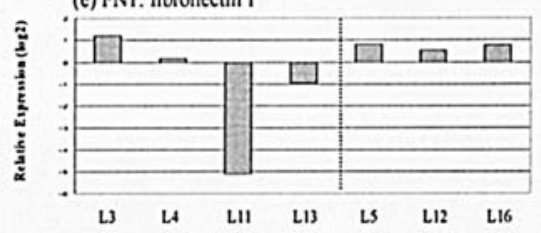

(h) RPS10: ribosomal protein S10

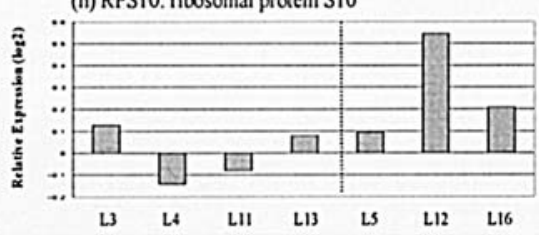

(b) EEFIG: eukaryotic translation elongation factor 1 .

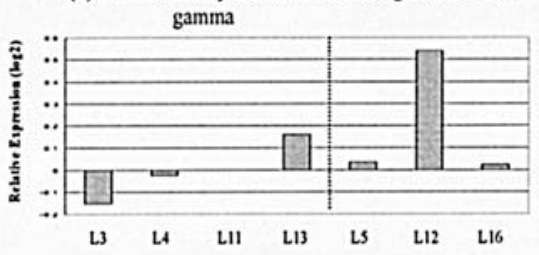

(d) HLA-C: MHC, class 1, C
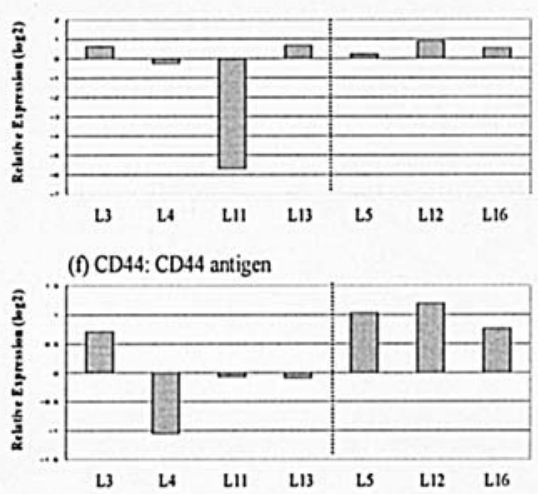

Figure 3. Semi-quantitative RT-PCR of the up- or down-regulated genes randomly selected from an HBV pool based on EST frequency. Total RNAs were extracted from HBV-HCC cell lines (L3, SNU475; L4, SNU368; L11, SNU354; L13, SNU387) and HCV-HCC lines (L5, HLK1; L12, JSHC; L16, HLK3). (A) Up-regulated and (B) down-regulated genes in the HBV pool. The transcript levels of the target genes were calculated using the same method described in Fig. 1, except that the transcript levels of target genes were calculated relative to the average amount of target gene in HCV pool (A) or relative to that of HBV cells (B). AKR1CN indicates the AKR1C family including AKR1C1, AKR1C2 and AKR1C3. 
Patient 1

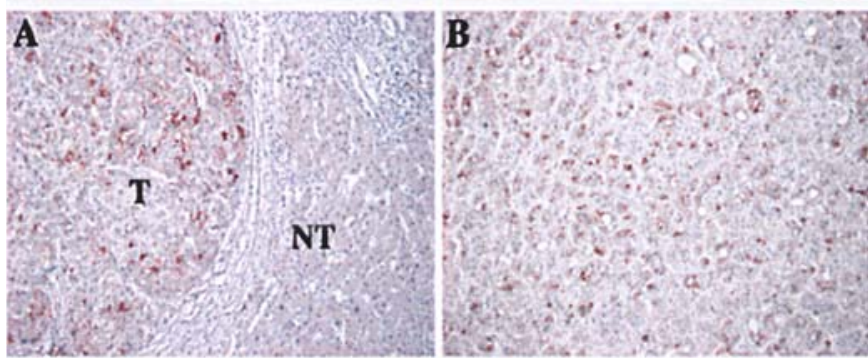

Figure 4. Immunohistochemistry of ANXA2 in HCC tissues. T represents the tumor region of $\mathrm{HCC}$, and NT the non-tumor region. Original magnification, $\mathrm{x} 100$ (patient 1) and x200 (patient 2).

for the seven up-regulated genes and seven down-regulated genes that had a high expressional difference between the HBV pool and HCV pool. The genes selected as up-regulated genes in the HBV pool were highly expressed in most of the HBV pool (Fig. 3A), but expressed at low levels or not expressed in most of the HCV pool. On the other hand, most of the down-regulated genes were expressed at lower levels in the HBV pool compared to the HCV pool (Fig. 3B).

Verification of protein levels for selected genes using immunohistochemistry. To verify protein levels for the genes confirmed by semi-quantitative RT-PCR, an immunohistochemical analysis of 13 human liver cancer tissues, mainly comprised of well- to moderately differentiated grade I or II tumors, was performed. ANXA2 and ENO1 were selected as target genes for $\mathrm{HCC}$, as antibodies were available and proteins previously confirmed to be related to HCC were excluded.

Among 13 human liver cancer tissues, the ANXA2 protein was shown to be highly expressed in the $10 \mathrm{HCC}$ tumor tissues compared to their corresponding non-tumor tissues. As shown in Fig. 4, it was highly expressed in the HCC region (T) compared with the non-tumor liver region (NT), and distributed mainly in the cytosol and membrane regions. On the other hand, ENO1 proteins were not detected in either normal liver or HCC tumor tissues in our study. This is thought to be due to the low reactivity of antibodies against ENO1. These results indicate that an increase in mRNA levels for target genes such as ANXA2 in HCC are coupled to the protein levels. In addition, these results suggest that the selected target genes may be possible candidate markers for the identification of HCC.

\section{Discussion}

A global gene expression analysis of human cancer may provide important clues in understanding liver cancer oncogenesis and lead to improvements in predicting its clinical behavior. Using an analysis of EST frequency, we examined the difference in gene expression profiles between normal liver tissues and HCC cells, as well as between HBVpositive and $\mathrm{HCV}$-associated HCC. Although we performed the gene expression analysis between normal liver tissues and $\mathrm{HCC}$ cell lines because normal liver cell lines were not available, data from these sets are consistent with RT-PCR data from HCC tissues and their corresponding non-tumor tissues. All HCC cell lines used in this study were obtained from Korean liver cancer patients. It has been reported that specific characteristics of genetic alterations in the original tumors are maintained during the establishment of immortalized cancer cells and, as a result, there is rarely a difference in genetic changes between the cancer cell line and original tumor $(27,28)$. Our results are consistent with these reports in that the EST frequency data from HCC cell lines was in general agreement with RT-PCR data for the HCC cell lines and tissues. Among the selected genes, at least 28 genes and well-known HCC-related genes, as confirmed by semiquantitative RT-PCR, could be identified as novel genes related to HCC, although some belong to the same functional category as genes previously reported to be related to liver cancer. These expression profiles may be useful for elucidating the molecular carcinogenesis of HCC, especially HBV- and $\mathrm{HCV}$-associated HCC.

The gene expression profile between normal liver tissues and HCC cells showed that genes involved in the glycolytic pathway such as $L D H A, E N O 1$ and PKM2 were increased in $\mathrm{HCC}$, which is in agreement with other studies that reported an increase in glycolysis in many types of cancer $(33,34)$. These glycolytic enzymes are known to be a hypoxia-inducible factor in other forms of cancer (35). This result indicates that the HIF-1 $\alpha$ signaling pathway might be related to the pathogenesis and progression of HCC. Several genes involved in protein translation were also highly expressed in HCC. Although most are known in HCC and in other cancers (36-38), RPL4, RPL10 and RPL13, which were expressed at high levels in human HCC tissues with a frequency of $>70 \%$, have not been reported to be related to liver cancer, including LDHA and ENOI of the glycolytic pathway. The up-regulation of these genes was shown to be higher in grade III/IV carcinoma compared with those in grade I/II of HCC. Generally, HCC appears to develop as well-differentiated tumors (Edmondson grade I), then progress to moderately or poorly differentiated states (Edmondson grade II, III, or IV). In this respect, the expression of these genes was preferentially increased in moderately to poorly differentiated tumors, implying that an increased rate of protein synthesis is a major characteristic of tumor progression. In addition, heat shock proteins were found to be preferentially and highly expressed in HCC. It has been reported that HSP90 was identified as an essential host factor for hepatitis B virus replication (39) and HSP70 as a molecular marker for early HCC (40). These heat shock proteins are also known to be up-regulated in many cancers (41). Since components related to survival and apoptotic pathways are regulated by interactions with molecular chaperones such as the HSP70 and HSP90 family (41), these heat shock proteins may be a useful target region for the molecular prognosis and treatment of liver cancer. On the other hand, several genes for proteins associated with the metabolism of alcohol, drugs, glucose, lipids, and amino acids and in respiratory chain complexes were down-regulated in liver cancer. In addition, the levels of a number of liverspecific proteins such as albumin, transferrin, coagulation factor, and complement components were decreased, as has been reported previously (20). Among the down-regulated genes, $A M B P, G C$, SERPINC1 and $A 1 B G$ might be also 
candidates for the diagnosis and treatment of liver cancer because they are known to be immune-related proteins or plasma proteins.

We also attempted to establish links between gene expression and the viral status of HCC. Comparative analysis of HBV- and HCV-associated HCC cell lines revealed that many ribosomal-related genes such as RPL family genes were up-regulated in $\mathrm{HBV}$-associated $\mathrm{HCC}$ cell lines (HBVHCCs) in comparison to HCV-associated HCC cell lines (HCV-HCCs), suggesting the activation of protein translation in HBV-HCCs. This observation is consistent with the previous report that major classes of genes encoding ribosomal proteins were up-regulated by the HBX protein (19). In addition, genes involved in extracellular matrix and cytoskeletal organization, such as ANXA2, KRT8, CKAP4, KRT7 and $C F L 1$, were shown to be up-regulated in HBV-HCCs, as well as genes such as $K$-ALPHA-1, ANXA1, ACTB, and ANXA5 in $\mathrm{HCV}-\mathrm{HCCs}$. Our results support the hypothesis that the deregulation of genes encoding proteins associated with the cytoskeleton play a role in liver carcinogenesis (42). These findings also indicate that the pathway for liver carcinogenesis in the cytoskeleton may be different between HBV-HCCs and HCV-HCCs. A large number of genes implicated in the metabolism of xenobiotics, lipids, carbohydrates, nitric oxide and leukotriene were also overexpressed in HBV-HCCs. Most of these genes encode for key enzymes for chemotherapeutic drugs or xenobiotic carcinogens. In particular, AKR1C1, AKR1C2 and AKR1C3, which are members of AKR1C (aldo-keto reductase family 1 , member $\mathrm{C}$ ), were highly overexpressed in HBV-HCCs. These enzymes catalyze the conversion of aldehydes and ketones to the corresponding alcohols utilizing NADH and/or NADPH as cofactors. Enhanced expression of these enzymes suggests that a greater contribution of carcinogenic metabolites may be involved in the mechanism of HBV-specific hepatocarcinogenesis. These findings are consistent with previous reports on the overexpression of $A K R 1 D 1$ in HBV-HCC in comparison to HCV-HCCs (43), but not in complete agreement with previously reported findings such as overexpression of AKRIDI (44) and AKRIC4 (17) in HCV-HCC. On the other hand, genes of HLA-B and HLA-C were highly expressed in HCV-HCCs. Our results are consistent with previous observations of increased expression of $H L A-B$ and $H L A-C$ in human hepatoma cell lines that constitutively express the $\mathrm{HCV}$ open reading frame (45) and increased expression of $H L A-B$ in liver fibrosis associated with chronic $\mathrm{HCV}$ infection (46). In addition, cell adhesion genes such as FN1 and CD44 were found to be up-regulated in HCV-HCCs, but have not been reported to be related to human HCV-HCCs. Most obtained genes, which are expressed differently in the HBV HCCs vis-a-vis HCV-HCCs, were newly identified, although the up-regulation of genes such as tubulin and HMGAl in the HCV pool was in agreement with previous data (47). It has been suggested that liver carcinogenesis induced by HBV and $\mathrm{HCV}$, in addition to common genetic and epigenetic alterations, may involve distinct pathways (47). Our expression profiles suggest that hepatitis viruses affect the expression of dozens of genes in HCC in a type-specific manner, thus invoking slightly different mechanisms of carcinogenesis. The identification of genes defining virus type-specific expression profiles would contribute to our ability to develop virus type-dependent treatment regimens.

Annexins are calcium-dependent phospholipid-binding proteins that play a role in the regulation of cellular growth and in signal transduction pathways (48). They are highly variable in their $\mathrm{N}$-terminal region, which is known to mediate the specific functions of individual annexins. Our results indicate that transcripts of $A N X A 2$ are overexpressed in HCC, especially in HBV-HCCs compared to the HCVHCCs, although ANXA1 and ANXA5 are slightly overexpressed in HCV-HCCs (data not shown). ANXA2 has been reported to be increased in colorectal cancer (49), but decreased in prostate cancer (50). These reports indicate that these proteins have different functions, such as in tumor progression or tumor suppression, depending on the cancer type or specific stage. The expression of ANXA2 in liver cancer has not yet been reported. Using immunohistochemistry, overexpression of the ANXA2 protein was also confirmed in HCC tissues. These results indicate that an increase in the mRNA level of ANXA2 in HCC tissues coupled with that of the protein level and change in the amount produced are associated with carcinogenesis in HCC. From these results, ANXA2 could be used as a marker for HCC.

We collected a total of approximately 21,000 unique ESTs (data not shown), and comprehensive cDNA microarray analyses using these clinical samples from several types of liver cancers are underway. In the gene expression profiling, our analysis using EST frequency has the advantage of permitting candidate genes to be selected without bias in comparison with the microarray analysis for only spotted genes. With the data obtained from EST frequency, further studies should provide a valuable resource for our understanding of liver cancer by revealing specific patterns that may reflect the prognosis and drug sensitivity of tumor cells, and identifying genes that are involved in the malignant transformation, progression, and metastasis of tumors. By raising antibodies against the products of these genes, we hope to identify new serum markers for the detection and diagnosis of HCC, and perhaps new candidate targets for treatment.

\section{Acknowledgements}

This work was supported by a grant from the 21C Frontier Functional Human Genome Project from the Ministry of Science and Technology of Korea. We thank Hong-Seog Park, Hee-Young Ahn, Mi-Young Chu, Ju-yeon Lee, and Tae-Hoon Song for their excellent technical support in EST sequencing, and Sung-Soo Kang for the bioinformatic analysis of ESTs. We also thank Dae-Ghon Kim of Chonbuk National University for the gift of HCV-associated $\mathrm{HCC}$ cell lines, and Young-il Yeomof KRIBB for the arrangement of HCC tissues.

\section{References}

1. Kasai Y, Takeda S and Takagi H: Pathogenesis of hepatocellular carcinoma: a review from the viewpoint of molecular analysis. Semin Surg Oncol 12: 155-159, 1996.

2. Parkin DM, Pisani P and Ferlay J: Global cancer statistics. CA Cancer J Clin 49: 33-64, 1999.

3. Okuda K, Fujimoto I, Hanai A and Urano Y: Changing incidence of hepatocellular carcinoma in Japan. Cancer Res 47: 4967-4972, 1987. 
4. Kim JW and Wang XW: Gene expression profiling of preneoplastic liver disease and liver cancer: a new era for improved early detection and treatment of these deadly diseases? Carcinogenesis 24: 363-369, 2003.

5. Murakami Y, Hayashi K, Hirohashi $\mathrm{S}$ and Sekiya T: Aberrations of the tumor suppressor p53 and retinoblastoma genes in human hepatocellular carcinomas. Cancer Res 51: 5520-5525, 1991.

6. Nhieu JT, Renard CA, Wei Y, Cherqui D, Zafrani ES and Buendia MA: Nuclear accumulation of mutated beta-catenin in hepatocellular carcinoma is associated with increased cell proliferation. Am J Pathol 155: 703-710, 1999.

7. Peng SY, Lai PL and Hsu HC: Amplification of the c-myc gene in human hepatocellular carcinoma: biologic significance. J Formos Med Assoc 92: 866-870, 1993.

8. Nishida N, Fukuda Y, Komeda T, Kita R, Sando T, Furukawa M, Amenomori M, Shibagaki I, Nakao K, Ikenaga M, et al: Amplification and overexpression of the cyclin D1 gene in aggressive human hepatocellular carcinoma. Cancer Res 54: 3107-3110, 1994

9. Kuroki T, Fujiwara Y, Tsuchiya E, Nakamori S, Imaoka S, Kanematsu T and Nakamura Y: Accumulation of genetic changes during development and progression of hepatocellular carcinoma: loss of heterozygosity of chromosome arm $1 \mathrm{p}$ occurs at an early stage of hepatocarcinogenesis. Genes Chromosomes Cancer 13: 163-167, 1995.

10. De Souza AT, Hankins GR, Washington MK, Fine RL, Orton TC and Jirtle RL: Frequent loss of heterozygosity on $6 \mathrm{q}$ at the mannose 6-phosphate/insulin-like growth factor II receptor locus in human hepatocellular tumors. Oncogene 10: 1725-1729, 1995.

11. Nishida N, Fukuda Y, Kokuryu H, Sadamoto T, Isowa G, Honda K, Yamaoka Y, Ikenaga M, Imura H and Ishizaki K: Accumulation of allelic loss on arms of chromosomes 13q, 16q and $17 \mathrm{p}$ in the advanced stages of human hepatocellular carcinoma. Int J Cancer 51: 862-868, 1992.

12. Ito N, Kawata S, Tamura S, Takaishi K, Shirai Y, Kiso S, Yabuuchi I, Matsuda Y, Nishioka M and Tarui S: Elevated levels of transforming growth factor beta messenger RNA and its polypeptide in human hepatocellular carcinoma. Cancer Res 51: 4080-4083, 1991

13. Cavin LG, Romieu-Mourez R, Panta GR, Sun J, Factor VM, Thorgeirsson SS, Sonenshein GE and Arsura M: Inhibition of CK2 activity by TGF-beta1 promotes IkappaB-alpha protein stabilization and apoptosis of immortalized hepatocytes. Hepatology 38: 1540-1551, 2003

14. Shirota Y, Kaneko S, Honda M, Kawai HF and Kobayashi K: Identification of differentially expressed genes in hepatocellular carcinoma with cDNA microarrays. Hepatology 33: 832-840, 2001.

15. Xu XR, Huang J, Xu ZG, Qian BZ, Zhu ZD, Yan Q, Cai T, Zhang X, Xiao HS, Qu J, Liu F, Huang QH, Cheng ZH, Li NG, Du JJ, Hu W, Shen KT, Lu G, Fu G, Zhong M, Xu SH, Gu WY, Huang W, Zhao XT, Hu GX, Gu JR, Chen Z and Han ZG: Insight into hepatocellular carcinogenesis at transcriptome level by comparing gene expression profiles of hepatocellular carcinoma with those of corresponding noncancerous liver. Proc Natl Acad Sci USA 98: 15089-15094, 2001.

16. Suriawinata A and Xu R: An update on the molecular genetics of hepatocellular carcinoma. Semin Liver Dis 24: 77-88, 2004.

17. Okabe H, Satoh S, Kato T, Kitahara O, Yanagawa R, Yamaoka Y, Tsunoda T, Furukawa Y and Nakamura Y: Genome-wide analysis of gene expression in human hepatocellular carcinomas using cDNA microarray: identification of genes involved in viral carcinogenesis and tumor progression. Cancer Res 61: 2129-2137, 2001

18. Yamashita T, Kaneko S, Hashimoto S, Sato T, Nagai S, Toyoda N, Suzuki T, Kobayashi K and Matsushima K: Serial analysis of gene expression in chronic hepatitis $\mathrm{C}$ and hepatocellular carcinoma. Biochem Biophys Res Commun 282: 647-654, 2001.

19. Wu CG, Forgues M, Siddique S, Farnsworth J, Valerie K and Wang XW: SAGE transcript profiles of normal primary human hepatocytes expressing oncogenic hepatitis $\mathrm{B}$ virus $\mathrm{X}$ protein. FASEB J 16: 1665-1667, 2002.

20. Chen X. Cheung ST, So S, Fan ST, Barry C, Higgins J, Lai KM, Ji J, Dudoit S, Ng IO, Van De Rijn M, Botstein D and Brown PO: Gene expression patterns in human liver cancers. Mol Biol Cell 13: 1929-1939, 2002.
21. Tackels-Horne D, Goodman MD, Williams AJ, Wilson DJ, Eskandari T, Vogt LM, Boland JF, Scherf U and Vockley JG: Identification of differentially expressed genes in hepatocellular carcinoma and metastatic liver tumors by oligonucleotide expression profiling. Cancer 92: 395-405, 2001.

22. Adams MD, Kelley JM, Gocayne JD, Dubnick M, Xiao H, Polymeropoulos MH, Merril CR, Wu A, Olde B, Moreno RF, et al: Complementary DNA sequencing: expressed sequence tags and human genome project. Science 252: 1651-1656, 1991 .

23. Okubo K, Hori N, Matoba R, Niiyama T, Fukushima A, Kojima Y and Matsubara K: Large scale cDNA sequencing for analysis of quantitative and qualitative aspects of gene expression. Nat Genet 2: 173-179, 1992.

24. Mao M, Fu G, Wu JS, Zhang QH, Zhou J, Kan LX, Huang QH, He KL, Gu BW, Han ZG, Shen Y, Gu J, Yu YP, Xu SH, Wang YX, Chen SJ and Chen Z: Identification of genes expressed in human CD34(+) hematopoietic stem/progenitor cells by expressed sequence tags and efficient full-length cDNA cloning. Proc Natl Acad Sci USA 95: 8175-8180, 1998.

25. Kato S, Sekine S, Oh SW, Kim NS, Umezawa Y, Abe N, Yokoyama-Kobayashi $\mathrm{M}$ and Aoki T: Construction of a human full-length cDNA bank. Gene 150: 243-250, 1994.

26. Maruyama K and Sugano S: Oligo-capping: a simple method to replace the cap structure of eukaryotic mRNAs with oligoribonucleotides. Gene 138: 171-174, 1994.

27. Park JG, Lee JH, Kang MS, Park KJ, Jeon YM, Lee HJ, Kwon HS, Park HS, Yeo KS, Lee KU, et al: Characterization of cell lines established from human hepatocellular carcinoma. Int J Cancer 62: 276-282, 1995.

28. Kim DG, Park SY, You KR, Lee GB, Kim H, Moon WS, Chun YH and Park SH: Establishment and characterization of chromosomal aberrations in human cholangiocarcinoma cell lines by cross-species color banding. Genes Chromosomes Cancer 30: 48-56, 2001.

29. Edmondson HA and Steiner PE: Primary carcinoma of the liver: a study of 100 cases among 48,900 necropsies. Cancer 7: 462-503, 1954.

30. Kim NS, Hahn Y, Oh JH, Lee JY, Oh KJ, Kim JM, Park HS, Kim S, Song KS, Rho SM, Yoo HS and Kim YS: Gene cataloging and expression profiling in human gastric cancer cells by expressed sequence tags. Genomics 83: 1024-1045, 2004.

31. Audic S and Claverie JM: The significance of digital gene expression profiles. Genome Res 7: 986-995, 1997.

32. Kim JM, Sohn HY, Yoon SY, Oh JH, Yang JO, Kim JH, Song KS, Rho SM, Yoo HS, Kim YS, Kim JG and Kim NS: Identification of gastric cancer-related genes using a cDNA microarray containing novel expressed sequence tags expressed in gastric cancer cells. Clin Cancer Res 11: 473-482, 2005.

33. Weber G: Enzymology of cancer cells (first of two parts). N Engl J Med 296: 486-492, 1977.

34. Weber G: Enzymology of cancer cells (second of two parts). N Engl J Med 296: 541-551, 1977.

35. Naughton DP: Hypoxia-induced upregulation of the glycolytic enzyme glucose-6-phosphate isomerase perpetuates rheumatoid arthritis. Med Hypotheses 60: 332-334, 2003.

36. Shuda M, Kondoh N, Tanaka K, Ryo A, Wakatsuki T, Hada A, Goseki N, Igari T, Hatsuse K, Aihara T, Horiuchi S, Shichita M, Yamamoto N and Yamamoto M: Enhanced expression of translation factor mRNAs in hepatocellular carcinoma. Anticancer Res 20: 2489-2494, 2000.

37. Kondoh N, Shuda M, Tanaka K, Wakatsuki T, Hada A and Yamamoto M: Enhanced expression of S8, L12, L23a, L27 and L30 ribosomal protein mRNAs in human hepatocellular carcinoma. Anticancer Res 21: 2429-2433, 2001

38. Kim JH, You KR, Kim IH, Cho BH, Kim CY and Kim DG: Overexpression of the ribosomal protein L36a gene is associated with cellular proliferation in hepatocellular carcinoma. Hepatology 39: 129-138, 2004

39. Hu J and Seeger C: Hsp90 is required for the activity of a hepatitis B virus reverse transcriptase. Proc Natl Acad Sci USA 93: 1060-1064, 1996

40. Chuma M, Sakamoto M, Yamazaki K, Ohta T, Ohki M, Asaka M and Hirohashi S: Expression profiling in multistage hepatocarcinogenesis: identification of HSP70 as a molecular marker of early hepatocellular carcinoma. Hepatology 37: 198-207, 2003.

41. Mosser DD and Morimoto RI: Molecular chaperones and the stress of oncogenesis. Oncogene 23: 2907-2918, 2004. 
42. Le Bail B, Faouzi S, Boussarie L, Balabaud C, Bioulac-Sage P and Rosenbaum J: Extracellular matrix composition and integrin expression in early hepatocarcinogenesis in human cirrhotic liver. J Pathol 181: 330-337, 1997.

43. Iizuka N, Oka M, Yamada-Okabe H, Hamada K, Nakayama H, Mori N, Tamesa T, Okada T, Takemoto N, Matoba K, Takashima M, Sakamoto K, Tangoku A, Miyamoto T, Uchimura S and Hamamoto Y: Molecular signature in three types of hepatocellular carcinoma with different viral origin by oligonucleotide microarray. Int J Oncol 24: 565-574, 2004.

44. Iizuka N, Oka M, Yamada-Okabe H, Mori N, Tamesa T, Okada T, Takemoto N, Tangoku A, Hamada K, Nakayama H, Miyamoto T, Uchimura $\mathrm{S}$ and Hamamoto $\mathrm{Y}$ : Comparison of gene expression profiles between hepatitis B virus- and hepatitis C virus-infected hepatocellular carcinoma by oligonucleotide microarray data on the basis of a supervised learning method. Cancer Res 62: 3939-3944, 2002

45. Aizaki H, Harada T, Otsuka M, Seki N, Matsuda M, Li YW, Kawakami H, Matsuura Y, Miyamura T and Suzuki T: Expression profiling of liver cell lines expressing entire or parts of hepatitis C virus open reading frame. Hepatology 36: 1431-1438, 2002.
46. Bieche I, Asselah T, Laurendeau I, Vidaud D, Degot C, Paradis V, Bedossa P, Valla DC, Marcellin P and Vidaud M: Molecular profiling of early stage liver fibrosis in patients with chronic hepatitis C virus infection. Virology 332: 130-144, 2005.

47. Delpuech O, Trabut JB, Carnot F, Feuillard J, Brechot C and Kremsdorf D: Identification, using cDNA macroarray analysis, of distinct gene expression profiles associated with pathological and virological features of hepatocellular carcinoma. Oncogene 21: 2926-2937, 2002

48. Gerke V and Moss SE: Annexins: from structure to function. Physiol Rev 82: 331-371, 2002.

49. Tomonaga T, Matsushita K, Yamaguchi S, Oh-Ishi M, Kodera Y, Maeda T, Shimada H, Ochiai T and Nomura F: Identification of altered protein expression and post-translational modifications in primary colorectal cancer by using agarose two-dimensional gel electrophoresis. Clin Cancer Res 10: 2007-2014, 2004.

50. Chetcuti A, Margan SH, Russell P, Mann S, Millar DS, Clark SJ, Rogers J, Handelsman DJ and Dong Q: Loss of annexin II heavy and light chains in prostate cancer and its precursors. Cancer Res 61: 6331-6334, 2001. 